\title{
Observed Increases in Summer Apparent Temperature over China in the Past 50 Years
}

\author{
Wenkai Li, Shuzhen Hu, Zongmei Pan, Xiaoyun Su, Xinyue Luo, and Yijuan Wang \\ Key Laboratory of Meteorological Disaster, Ministry of Education (KLME)/ \\ Joint International Research Laboratory of Climate and Environment Change (ILCEC)/ \\ Collaborative Innovation Center on Forecast and Evaluation of Meteorological Disasters (CIC-FEMD), \\ Nanjing University of Information Science \& Technology, Nanjing, China
}

\begin{abstract}
The apparent temperature (APT), or human-perceived temperature, is commonly defined as a function of the surface air temperature (SAT), vapour pressure (or humidity) and wind speed. This paper demonstrates that the APT over China, as revealed by daily station-observed data, has generally increased faster than the SAT during summertime in the past 50 years $(1968-2017)$. The rate of increase in APT was significantly faster than that of SAT in $60.1 \%$ of stations, and the difference between the average Chinawide APT and SAT was $0.11^{\circ} \mathrm{C}$ decade $^{-1}$. This phenomenon is occurring nationwide, but it is more intense over western, north-eastern and eastern coastal China. The more rapid increasing trend in APT indicates that human beings actually experience surplus heat stress under a certain change in SAT, and the increased SAT explains $67.0 \%$ of the average APT warming for the country, contributing to the change in the base APT. Apart from the increasing SAT, a decrease in surface wind speed and an increase in surface vapour pressure have also been observed, contributing to $21.6 \%$ of the increase in APT and explaining the remaining $11.4 \%$, respectively.
\end{abstract}

(Citation: Li, W., S. Hu, Z. Pan, X. Su, X. Luo, and Y. Wang, 2019: Observed increases in summer apparent temperature over China in the past 50 years. SOLA, 15, 47-51, doi:10.2151/sola. 2019-010.)

\section{Introduction}

Global temperature has risen rapidly in recent decades (Alexander et al. 2006; Hansen et al. 2006; Kaufmann et al. 2011; Seneviratne et al. 2014; Sun et al. 2017; Hawkins et al. 2017; Lee et al. 2018), and this warming greatly affects our living environment (Wang et al. 2011; Tao and Zhang 2011; Coumou et al. 2013; Howe et al. 2013; Kraaijenbrink et al. 2017; Garcia et al. 2018). Recent studies of climate change in China have also shown that significant increases in temperature have occurred (Zhou and Ren 2011; Li et al. 2012; Qi and Wang 2012; Wang et al. 2017; Dong et al. 2018); temperatures have risen more rapidly since the $1950 \mathrm{~s}$, with a rate of increase of more than $0.25^{\circ} \mathrm{C}$ decade over China (Ren et al. 2017). The projected temperature also show remarkable increases (Lee et al. 2014; Li et al. 2018a). With rising temperatures, heatwaves and droughts are increasing in frequency and intensity (Zhang et al. 2009; Ding et al. 2010; Zhang et al. 2013; Chen and Sun 2015; Xia et al. 2016), but apart from changes in temperature, other meteorological conditions, such as land surface humidity and wind speed, have also changed in the context of global warming in recent decades (Jiang et al. 2010; Guo et al. 2011; Song et al. 2012; Lu et al. 2014; Wu et al. 2017a). An overall decline in wind speed has been detected (Jiang et al. 2010; Guo et al. 2011; Wu et al. 2017a), and the surface humidity has changed as well, although with some regional differences (Song et al. 2012).

Corresponding author: Wenkai Li, Nanjing University of Information Science \& Technology, 210044 Nanjing, China. E-mail: wenkai@nuist.edu.cn.
The apparent temperature (APT), or human-perceived temperature, is commonly defined as a function of the surface air temperature (SAT), vapour pressure (or humidity) and wind speed (Steadman 1994). A higher vapour pressure (i.e., wetter condition) or a lower wind speed causes the human body to experience surplus heat stress under the same SAT condition. The APT is used in studies of heat-related human health to quantify the human sensation of environmental conditions (e.g., Alessandrini et al. 2011; Wichmann et al. 2011; Garland et al. 2015), and some studies have demonstrated that global warming raises APT more than SAT (Allen and Sheridan 2016; Wu et al. 2017b; Gao et al. 2018; Li et al. 2018b; Wang et al. 2019), meaning that human beings may actually sense an increase in temperature greater than the increase in SAT. Recently, a few studies have reported the historical (Wu et al. 2017b; Wang et al. 2019) and projected (Gao et al. 2018) warming trends over China from the perspective of APT, but to our knowledge, a general look at the changes in APT for the country based on directly observed station data is still lacking. This work aims to study the summer APT over China over the last 50 years with a focus on the differences between the changes in APT and SAT, and the contributions of vapour pressure and wind speed to these differences were also analysed. The results might further confirm the surplus heat stress under global climate change.

\section{Data and methods}

\subsection{Station-observed dataset}

Station-observed daily data were obtained from the climate dataset from Chinese surface stations, which was provided by the National Meteorological Information Centre of the China Meteorological Administration (CMA). The CMA performed quality controls for this dataset, which covered the 1968-2017 period. This study focuses on the summertime, i.e., June to August, which is the warmest season in China. The daily mean, maximum and minimum 2-m SAT values, daily mean $2-\mathrm{m}$ relative humidity values and daily mean $10-\mathrm{m}$ wind speed values are directly obtained from this dataset.

There were 824 stations in the primary station dataset, but some values were missing. Prior to the analysis, the data were carefully examined, and the stations were selected based on the following criteria. If there were any missing temperature, relative humidity or wind speed values in one day for a station, all three meteorological variables were set as missing values for that day. For each station in one summer (92 days), if values were missing for 10 days or more, the station was set as missing for that year. The stations with 2 or more missing years were eliminated. According to these criteria, 770 stations were selected, and their locations are shown in Supplementary Fig. S1.

\subsection{Methods}

We estimated the APT from the SAT, surface relative humidity and wind speed using the station-observed data. There are many indices concerning human-perceived temperature. A brief summary of existing common indices can be referred in Blazejczyk (2012) and Buzan (2015). Some indices combine effects on the 
human organism of three meteorological variables: SAT, air humidity and wind speed, although some other indices take only two kinds of effects into account. Among these indices we select the universal APT for general weather conditions proposed by Steadman (1994). We use this index because it combines the effects of ambient temperature, vapour pressure (humidity-related) and wind speed, and is valid over a wide range of temperatures. The daily APT $\left(T_{\mathrm{APT}}\right.$; unit is $\left.{ }^{\circ} \mathrm{C}\right)$ is parameterized as a function of SAT $\left(T_{\mathrm{SAT}}\right.$; unit is $\left.{ }^{\circ} \mathrm{C}\right)$, actual vapour pressure $\left(e_{\mathrm{a}}\right.$; unit is $\left.\mathrm{hPa}\right)$ and wind speed $\left(v\right.$; unit is $\left.\mathrm{m} \mathrm{s}^{-1}\right)$ as follows:

$$
T_{\mathrm{APT}}=T_{\mathrm{SAT}}+0.33 \times e_{\mathrm{a}}-0.7 v-4.0 .
$$

Here, the $T_{\mathrm{SAT}}$ and $v$ are daily mean value directly obtained from the dataset, and the $e_{\mathrm{a}}$ is computed via equation as described in Allen et al. (1998):

$$
e_{\mathrm{a}}=\frac{R H_{\text {mean }}}{100}\left[\frac{e_{\mathrm{s}}\left(T_{\max }\right)+e_{\mathrm{s}}\left(T_{\min }\right)}{2}\right]
$$

where the $R H_{\text {mean }}$ is daily mean relative humidity, and the $e_{\mathrm{s}}\left(T_{\text {max }}\right)$ and $e_{\mathrm{s}}\left(T_{\min }\right)$ are saturation vapour pressure (unit is $\mathrm{hPa}$ ) at daily maximum SAT $\left(T_{\max }\right)$ and minimum SAT $\left(T_{\min }\right)$ respectively. The $e_{\mathrm{s}}\left(T_{\max }\right)$ and $e_{\mathrm{s}}\left(T_{\min }\right)$ can be calculated from $T_{\max }$ or $T_{\min }$ :

$$
e_{\mathrm{s}}(T)=6.108 \exp \left(\frac{17.27 T}{T+237.3}\right)
$$

Season-averaging was then performed for each summer to obtain the interannual APT for each station. Linear regression coefficients between meteorological variables and time (yearly) were calculated to represent the change trend. Statistical significance for the regression was considered at two-tailed $95 \%$ level in this study.

\section{Results}

\subsection{Observed increases in summer apparent temperature}

The spatial distribution patterns of the temporal trends in summer APT for each station are shown in Fig. 1a. An overall trend of warming APT is observed over China, and the regional warming trends are especially obvious and even reach $0.5^{\circ} \mathrm{C}$ decade $^{-1}$ over north-western and north-eastern China, the eastern Tibetan Plateau and the southeast coast of the country. A decreasing trend and a non-significant trend occur across some scattered stations over inland central China but account for only a small proportion of the total stations. The distribution of the proportions of the significant trends in APT for the stations is shown in Fig. $2 \mathrm{a}$, and most stations with a significant trend show increasing APT at values of $0.2-0.6^{\circ} \mathrm{C}$ decade ${ }^{-1}$ with the proportion of the trend peaking at $0.4^{\circ} \mathrm{C}$ decade $^{-1}$. These stations with significantly increasing APT account for $82.6 \%$ of the total of 770 stations. In contrast, only $1.0 \%$ of the stations show significantly decreasing APT, and the remaining $16.4 \%$ exhibit non-significant changes. In terms of the temporal evolution over all of China (red lines in Fig. 3), APT increased $0.34^{\circ} \mathrm{C}$ decade $^{-1}$ during the summers of 1968-2017. Generally, APT increases significantly at the national spatial scales.

SAT also shows an overall warming trend over China (Supplementary Fig. S2a). Similar to the APT, warming trends are obvious over north-western and north-eastern China, the eastern Tibetan Plateau and the southeast coast of the country. The decreasing and non-significant trends occur in some stations over central inland China. The distribution of the proportion of the trend in SAT for all stations is shown in Supplementary Fig. S3a. Most stations with a significant trend exhibit increasing SAT at values of $0.1-0.5^{\circ} \mathrm{C}$ decade $^{-1}$, and the proportion peaks at a trend of $0.3^{\circ} \mathrm{C}$ decade $^{-1}$. Of all 770 stations, $77.3 \%$ show significant increases in SAT, whereas only $1.0 \%$ show significant decreases and the remaining $21.7 \%$ show non-significant changes. Compared to the trend in APT, significant increases occur in slightly fewer stations
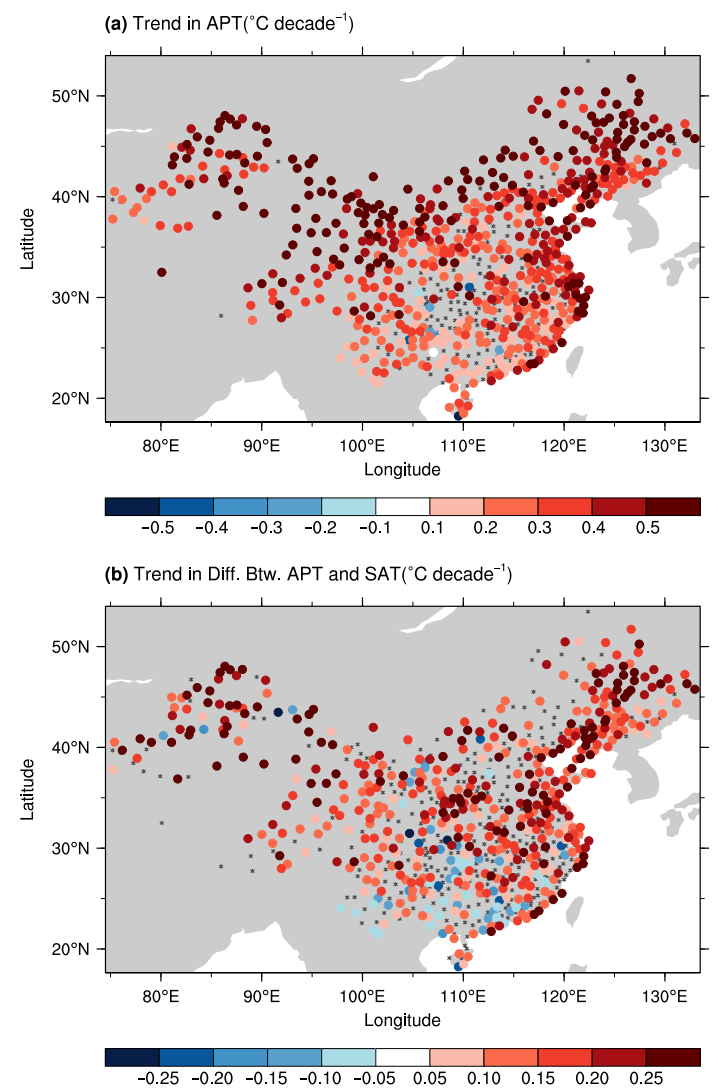

Fig. 1. (a) Linear trend in the apparent temperature (APT) in summer, 1968-2017. (b) is the same as (a) but shows the differences between the APT and surface air temperature (SAT). The unit is ${ }^{\circ} \mathrm{C}$ decade ${ }^{-1}$. Only trends that are statistically significant at the $95 \%$ confidence level are plotted in solid coloured circles, and asterisks (*) mark the locations of stations with non-significant trends. (a) APT

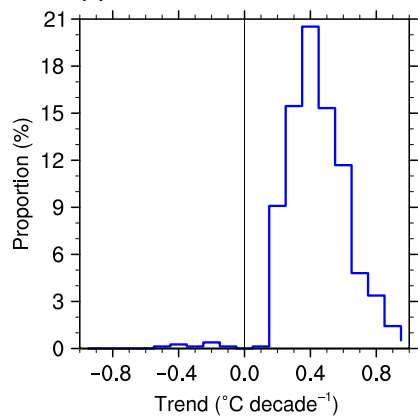

(b) Diff. Btw. APT and SAT

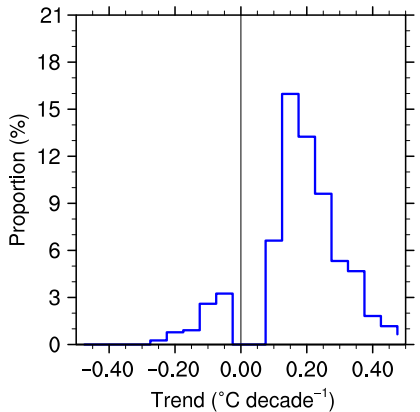

Fig. 2. (a) The distribution of the proportion of the trend in the apparent temperature (APT) for stations with significant trends shown in Fig. 1a. (b) is the same as (a), but the differences between the APT and the surface air temperature (SAT) are shown. The $x$-axis indicates the trend (unit is ${ }^{\circ} \mathrm{C}$ decade $\left.^{-1}\right)$, and the $y$-axis indicates the proportion of stations. The spacing of the bins used for (a) and (b) is $0.10^{\circ} \mathrm{C} \mathrm{decade}{ }^{-1}$ and $0.06^{\circ} \mathrm{C} \mathrm{decade}{ }^{-1}$, respectively.

with smaller change values. In terms of the China-wide temporal evolution (blue lines in Fig. 3), SAT increases $0.23^{\circ} \mathrm{C}$ decade $^{-1}$ during the summers of 1968-2017, which is smaller than the ATP change rate. Generally, SAT also significantly increases at the national spatial scale but with smaller change values than APT.

The above results demonstrate that both APT and SAT have significantly increased over China, but the rate of increase differs. The differences in the trends of the APT and SAT are shown in 


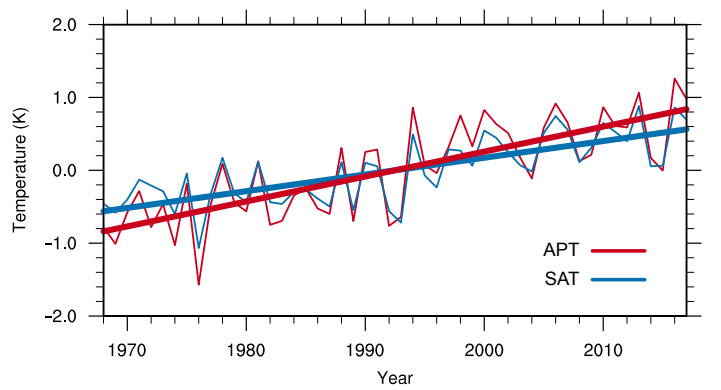

Fig. 3. Changes in the apparent temperature (APT; red lines) and surface air temperature (SAT; blue lines) over China in the summers of 19682017. The unit is ${ }^{\circ} \mathrm{C}$. Thick lines show yearly season-average values, and bold lines show their linear trends. The means for both APT and SAT have been removed.

Fig. $1 \mathrm{~b}$ and generally exhibit positive values; namely, the APT increases faster than the SAT. The positive differences are spread throughout the country except for some areas over central inland and south-western China. The positive differences are much more considerable over western, north-eastern and the east coast of China than other parts. The distribution of the proportion of the differences between the trends of APT and SAT are shown in Fig. $2 \mathrm{~b}$. Most stations with significantly different trends exhibit positive values of approximately $0.1-0.3^{\circ} \mathrm{C}$ decade $^{-1}$, and the proportion peaked at $0.15^{\circ} \mathrm{C}$ decade $^{-1}$. Of the 770 stations, $60.1 \%$ show significant positive differences at the $95 \%$ level, whereas $7.9 \%$ exhibit significant negative differences and the remaining $31.9 \%$ show non-significant differences. For the China-wide temporal evolution (red lines versus blue lines in Fig. 3), the linear trends in APT and SAT have different slopes. Obviously, the APT increases at a faster rate than SAT, and this difference is $0.11^{\circ} \mathrm{C}$ decade $^{-1}$ at the national scale. The faster rate of increase in APT indicates that human beings sense a greater increase in the temperature than the actual increase in SAT. This phenomenon is generally widespread across China and is more intense over western and north-eastern China as well as the east coast.

\subsection{Contribution of each factor}

As mentioned above, the SAT has generally increased over China over the last 50 years, which is consistent with previous studies (Zhou and Ren 2011; Li et al. 2012; Qi and Wang 2012; Wang et al. 2017; Dong et al. 2018), but the changes in vapour pressure and wind speed are somehow different. The change in vapour pressure is not as considerable as that of SAT (Supplementary Fig. S2b). There is a general increasing trend, but the spatial patterns are not as dominant as those of the APT or SAT. For all 770 stations, $40.6 \%$ exhibit a significant increasing trend, whereas $7.1 \%$ show a significant decreasing trend and the remaining $52.2 \%$ show a non-significant change (Supplementary Fig. S3b). The change in specific humidity also shows a general increasing trend (Supplementary Fig. S2c and Fig. S3c), and has very similar spatial distribution pattern as that in vapour pressure, indicating that the surface air is wetter than before. Under the global climate change, the increase of SAT may lead to increases of evaporation and water vapour in the atmosphere (Held and Soden 2006; Song et al. 2012). Meanwhile, wind speed weakens overall (Supplementary Fig. S2d). For the 770 stations, $61.3 \%$ show a significant decreasing trend, whereas $11.6 \%$ exhibit a significant increasing trend and the remaining $27.1 \%$ show a non-significant change (Supplementary Fig. S3d). The overall declines of wind speed detected here are consistent with existing research (Jiang et al. 2010; Guo et al. 2011; Wu et al. 2017a). They attribute the declines of wind speed to the weakening in the lower-tropospheric pressure-gradient force (Jiang et al. 2010; Guo et al. 2011) and land use and cover change (Wu et al. 2017a). The above results indicate that climate change in China is generally characterized by increased SAT and vapour pressure but decreased wind speed. The changes are occurring across the nation, but each meteorological

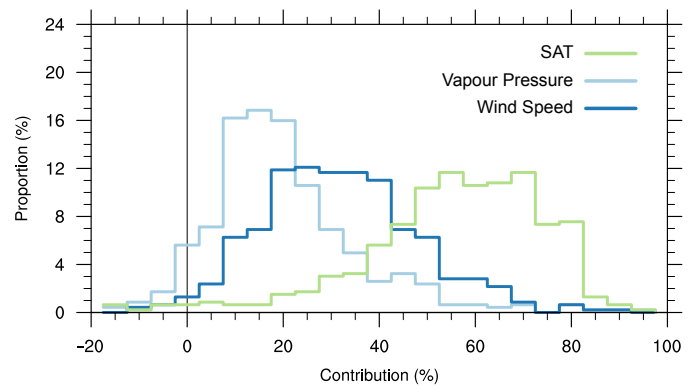

Fig. 4. The distributions of the proportions of the contributions of surface air temperature (SAT; green line), vapour pressure (light blue line) and wind speed (dark blue line) to the change in apparent temperature (APT). The $x$-axis indicates the contribution to APT (unit is \%), and the $y$-axis indicates the proportion of stations. The spacing of the bins is $5 \%$. The spatial distributions of the contributions in each station can be observed in Supplementary Fig. S4.

Table 1 Regional average contribution of surface air temperature (SAT), vapour pressure and wind speed to the change in apparent temperature (APT) over mainland China.

\begin{tabular}{ccc}
\hline SAT & Vapour Pressure & Wind Speed \\
\hline $67.0 \%$ & $11.4 \%$ & $21.6 \%$ \\
\hline
\end{tabular}

variable has some specific characteristics. In Section 3.1, we found that APT increases significantly faster than SAT in $60.1 \%$ of the total of the 770 stations, so to better understand the reasons for this phenomenon, we analysed the contributions of SAT, vapour pressure and wind speed to the increase in APT in the stations exhibiting significant positive differences.

The distribution of the proportions of the contribution induced by the three variables is shown in Fig. 4 for the stations showing significantly faster increases in APT than SAT. In addition, their spatial distributions are presented in Supplementary Fig. S4. Most of contributions from SAT to the stations are within $40-80 \%$ (green line in Fig. 4), and it is the most dominant among the three meteorological variables, indicating that it largely drives the increase in APT. Wetter vapour pressure and calmer wind speed contribute to an even faster rate of increase in APT. Most of the contributions from vapour pressure are within $0-30 \%$ (light blue line in Fig. 4) and are smaller than the contributions of SAT. Meanwhile, most of the contributions from wind speed are within 10-50\% (dark blue line in Fig. 4) and also smaller than contributions from SAT but greater than those from vapour pressure, indicating that wind speed is the secondary factor contributing to the faster increase in APT.

As indicated in Section 3.1 and Fig. 3, the APT increases faster than SAT for China as a whole, so for a complete comparison, the average relative contributions of each factor are also analysed for China. The China-wide average contributions of SAT, vapour pressure and wind speed are shown in Table 1, and SAT is the most dominant contributing factor $(67.0 \%)$. Wind speed is the second most important factor, contributing to $21.6 \%$ of the increase in APT, and vapour pressure makes a relatively small contribution that accounts for the remainder (11.4\%).

\section{Conclusion and discussion}

China has tended to be warmer in recent decades, but other meteorological conditions, such as land surface humidity and wind speed, have also been changing in this context. Changes in humidity and wind speed may influence the heat stress experienced by human beings, so to confirm this surplus heat stress under global climate change, we investigated the change in summer APT over China during in the past 50 years using station-observed data. An 
overall warming trend is observed in APT in China, and it shows a faster rate of increase than SAT. The faster increase in the change in APT is generally spread throughout China but is more intense over western and north-eastern China as well as the east coast. Of all the stations, $60.1 \%$ show a significantly faster increase in APT than SAT, and the difference in the rate of increase between APT and SAT over the entire country is $0.11^{\circ} \mathrm{C}$ decade ${ }^{-1}$.

The increased SAT explains $67.0 \%$ of the average China-wide warming of APT, so it is the base contributor to the change. Apart from the increasing APT and SAT, a decrease in surface wind speed and an increase in surface vapour pressure are observed. The lower wind speed and higher vapour pressure (i.e., wetter conditions) cause surplus heat stress to the human body under the same SAT condition. The decreasing wind speed is the second most important factor to the increase in APT and contributes $21.6 \%$ of the change, while vapour pressure explains the remainder $(11.4 \%)$.

The first aim of this work is to confirm the surplus heat stress under global climate change. A limitation of this study is that only one definition of APT was used. Apart from the formulation by Steadman (1994), there are other definitions of APT, so this work is more qualitative than quantitative to a certain extent. The current study is also limited by the lack of information on daily maximum and minimum relative humidity $\left(R H_{\max }\right.$ and $\left.R H_{\min }\right)$. Equation (2) is less desirable than Equations including all variables of daily $R H_{\max }, R H_{\min }, T_{\max }$ and $T_{\min }$ to calculate actual vapour pressur (Allen et al. 1998). Accurate data with high time- and spatial-resolution would help us to remove this limitation in future work. For example, dynamic downscaling provide additional details beyond global reanalysis or global climate simulation (Lee et al. 2014; Li et al. 2016). Meanwhile, China has been experiencing urbanization in recent decades, and it should be noted that the CMA meteorological stations tend to be in inhabited areas, which may exert some influence on the results. Therefore, the observed change includes the effects of urbanization.

\section{Acknowledgements}

This research is supported by the National Key Research and Development Program of China (2018YFC1505804), College Students' Practice Innovation Training Program of NUIST (2018 10300137), the Startup Foundation for Introducing Talent of NUIST. The daily climate data from the Chinese surface stations is available at http://cdc.nmic.cn. All figures were produced using the NCAR Command Language, version 6.5.0, which is free to the public (http://dx.doi.org/10.5065/D6WD3XH5).

Edited by: M. Sugi

\section{Supplements}

Supplementary Fig. S1 shows the locations of the stations used in this study. Supplementary Fig. S2 shows the linear trend in SAT, vapour pressure, specific humidity and wind speed, respectively. Supplementary Fig. S3 shows the distribution of the proportion of the trend for stations exhibiting significant changes in Supplementary Fig. S2. Supplementary Fig. S4 shows the spatial distribution pattern of the contribution induced by SAT, vapour pressure and wind speed, respectively.

\section{References}

Alessandrini, E., S. Z. Sajani, F. Scotto, R. Miglio, S. Marchesi, and P. Lauriola, 2011: Emergency ambulance dispatches and apparent temperature: A time series analysis in EmiliaRomagna, Italy. Environ. Res., 111, 1192-1200, doi:10.1016/ j.envres.2011.07.005.

Alexander, L. V., X. Zhang, T. C. Peterson, J. Caesar, B. Gleason, A. Tank, M. Haylock, D. Collins, B. Trewin, F. Rahimzadeh,
A. Tagipour, K. R. Kumar, J. Revadekar, G. Griffiths, L. Vincent, D. B. Stephenson, J. Burn, E. Aguilar, M. Brunet, M. Taylor, M. New, P. Zhai, M. Rusticucci, and J. L. Vazquez-Aguirre, 2006: Global observed changes in daily climate extremes of temperature and precipitation. J. Geophys. Res. Atmos., 111, D05109, doi:10.1029/2005jd006290.

Allen, M. J., and S. C. Sheridan, 2016: Spatio-temporal changes in heat waves and cold spells: An analysis of 55 U.S. cities. Phys. Geogr., 37, 189-209, doi:10.1080/02723646.2016. 1184078.

Allen, R. G., L. S. Pereira, D. Raes, and M. Smith, 1998: Crop Evapotranspiration - Guidelines for Computing Crop Water Requirements. FAO Irrigation and Drainage Paper 56 (Available online at http://www.fao.org/docrep/x0490e/ x0490e00.htm, accessed on 1 December 2018).

Blazejczyk, K., Y. Epstein, G. Jendritzky, H. Staiger, and B. Tinz, 2012: Comparison of UTCI to selected thermal indices. Int. J. Biometeor, 56, 515-535, doi:10.1007/s00484-011-0453-2.

Buzan, J. R., K. Oleson, and M. Huber, 2015: Implementation and comparison of a suite of heat stress metrics within the Community Land Model version 4.5. Geosci. Model Dev., 8, 151-170, doi:10.5194/gmd-8-151-2015.

Chen, H., and J. Sun, 2015: Changes in drought characteristics over China using the standardized precipitation evapotranspiration index. J. Climate, 28, 5430-5447, doi:10.1175/jclid-14-00707.1.

Coumou, D., A. Robinson, and S. Rahmstorf, 2013: Global increase in record-breaking monthly-mean temperatures. Climatic Change, 118, 771-782, doi:10.1007/s10584-0120668-1.

Ding, T., W. Qian, and Z. Yan, 2010: Changes in hot days and heat waves in China during 1961-2007. Int. J. Climatol., 30, 1452-1462, doi:10.1002/joc.1989.

Dong, S., Y. Sun, E. Aguilar, X. Zhang, T. C. Peterson, L. Song, and Y. Zhang, 2018: Observed changes in temperature extremes over Asia and their attribution. Climate Dyn., 51, 339-353, doi:10.1007/s00382-017-3927-z.

Gao, X.-J., J. Wu, Y. Shi, J. Wu, Z.-Y. Han, D.-F. Zhang, Y. Tong, R.-K. Li, Y. Xu, and F. Giorgi, 2018: Future changes in thermal comfort conditions over China based on multi-RegCM4 simulations. Atmos. Oceanic Sci. Lett., 11, 291-299, doi: 10.1080/16742834.2018.1471578.

Garcia, F. C., E. Bestion, R. Warfield, and G. Yvon-Durocher, 2018: Changes in temperature alter the relationship between biodiversity and ecosystem functioning. Proc. Natl. Acad. Sci. U.S.A., 115, 10989-10999, doi:10.1073/pnas.1805518115.

Garland, R. M., M. Matooane, F. A. Engelbrecht, M.-J. M. Bopape, W. A. Landman, M. Naidoo, J. van der Merwe, and C. Y. Wright, 2015: Regional projections of extreme apparent temperature days in Africa and the related potential risk to human health. Inter. J. Env. Res. Pub. Heal., 12, 1257712604, doi:10.3390/ijerph121012577.

Guo, H., M. Xu, and Q. Hu, 2011: Changes in near-surface wind speed in China: 1969-2005. Int. J. Climatol., 31, 349-358, doi:10.1002/joc. 2091.

Hansen, J., M. Sato, R. Ruedy, K. Lo, D. W. Lea, and M. MedinaElizade, 2006: Global temperature change. Proc. Natl. Acad. Sci. U.S.A., 103, 14288-14293, doi:10.1073/pnas. 0606291103.

Hawkins, E., P. Ortega, E. Suckling, A. Schurer, G. Hegerl, P. Jones, M. Joshi, T. J. Osborn, V. Masson-Delmotte, J. Mignot, P. Thorne, and G. J. van Oldenborgh, 2017: Estimating changes in global temperature since the preindustrial period. Bull. Amer. Meteor. Soc., 98, 1841-1856, doi: 10.1175/bams-d-16-0007.1.

Held, I. M., and B. J. Soden, 2006: Robust responses of the hydrological cycle to global warming. J. Climate, 19, 5686-5699, doi:10.1175/jcli3990.1.

Howe, P. D., E. M. Markowitz, T. M. Lee, C.-Y. Ko, and A. Leiserowitz, 2013: Global perceptions of local temperature change. Nat. Climate Change, 3, 352-356, doi:10.1038/ nclimate 1768. 
Jiang, Y., Y. Luo, Z. Zhao, and S. Tao, 2010: Changes in wind speed over China during 1956-2004. Theor. Appl. Climatol., 99, 421-430, doi:10.1007/s00704-009-0152-7.

Kaufmann, R. K., H. Kauppi, M. L. Mann, and J. H. Stock, 2011: Reconciling anthropogenic climate change with observed temperature 1998-2008. Proc. Natl. Acad. Sci. U.S.A., 108, 11790-11793, doi:10.1073/pnas.1102467108.

Kraaijenbrink, P. D. A., M. F. P. Bierkens, A. F. Lutz, and W. W. Immerzeel, 2017: Impact of a global temperature rise of 1.5 degrees Celsius on Asia's glaciers. Nature, 549, 257-260, doi:10.1038/nature23878.

Lee, J., S. Hong, E. Chang, M. Suh, and H. Kang, 2014: Assessment of future climate change over East Asia due to the RCP scenarios downscaled by GRIMs-RMP. Climate Dyn., 42, 733-747, doi:10.1007/s00382-013-1841-6.

Lee, J., Y. Xue, F. De Sales, I. Diallo, L. Marx, M. Ek, K. R. Sperber, and P. J. Gleckler, 2018: Evaluation of multidecadal UCLA-CFSv2 simulation and impact of interactive atmospheric-ocean feedback on global and regional variability. Climate Dyn. (in press). doi:10.1007/s00382-0184351-8.

Li, B., Y. Chen, and X. Shi, 2012: Why does the temperature rise faster in the arid region of northwest China? J. Geophys. Res. Atmos., 117, D16115, doi:10.1029/2012jd017953.

Li, D., T. Zhou, L. Zou, W. Zhang, and L. Zhang, 2018a: Extreme high-temperature events over East Asia in 1.5 degrees $\mathrm{C}$ and 2 degrees $\mathrm{C}$ warmer futures: Analysis of NCAR CESM low-warming experiments. Geophys. Res. Lett., 45, 15411550, doi:10.1002/2017gl076753.

Li, J., Y. D. Chen, T. Y. Gan, and N.-C. Lau, 2018b: Elevated increases in human-perceived temperature under climate warming. Nat. Climate Change, 8, 43-47, doi:10.1038/ s41558-017-0036-2.

Li, W., W. Guo, Y. Xue, C. Fu, and B. Qiu, 2016: Sensitivity of a regional climate model to land surface parameterization schemes for East Asian summer monsoon simulation. Climate Dyn., 47, 2293-2308, doi:10.1007/s00382-0152964-8.

Lu, E., Y. Zeng, Y. Luo, Y. Ding, W. Zhao, S. Liu, L. Gong, Y. Jiang, Z. Jiang, and H. Chen, 2014: Changes of summer precipitation in China: The dominance of frequency and intensity and linkage with changes in moisture and air temperature. J. Geophys. Res. Atmos., 119, 12575-12587, doi: $10.1002 / 2014 \mathrm{jd} 022456$.

Qi, L., and Y. Wang, 2012: Changes in the observed trends in extreme temperatures over China around 1990. J. Climate, 25, 5208-5222, doi:10.1175/jcli-d-11-00437.1.

Ren, G., Y. Ding, and G. Tang, 2017: An overview of Mainland China temperature change research. J. Meteor. Res., 31, 3-16, doi:10.1007/s13351-017-6195-2.

Seneviratne, S. I., M. G. Donat, B. Mueller, and L. V. Alexander, 2014: No pause in the increase of hot temperature extremes. Nat. Climate Change, 4, 161-163, doi:10.1038/nclimate 2145.

Song, Y., Y. Liu, and Y. Ding, 2012: A study of surface humidity changes in china during the recent 50 years. Acta Meteor. Sin., 26, 541-553, doi:10.1007/s13351-012-0501-9.
Steadman, R. G., 1994: Norms of apparent temperature in Australia. Aust. Meteor. Mag., 43, 1-16.

Sun, X., G. Ren, W. Xu, Q. Li, and Y. Ren, 2017: Global landsurface air temperature change based on the new CMA GLSAT data set. Sci. Bull., 62, 236-238, doi:10.1016/j.scib. 2017.01.017.

Tao, F., and Z. Zhang, 2011: Impacts of climate change as a function of global mean temperature: Maize productivity and water use in China. Climatic Change, 105, 409-432, doi: 10.1007/s10584-010-9883-9.

Wang, X., S. Piao, P. Ciais, J. Li, P. Friedlingstein, C. Koven, and A. Chen, 2011: Spring temperature change and its implication in the change of vegetation growth in North America from 1982 to 2006. Proc. Natl. Acad. Sci. U.S.A., 108, 1240-1245, doi:10.1073/pnas.1014425108.

Wang, Y., L. Chen, Z. Song, Z. Huang, E. Ge, L. Lin, and M. Luo, 2019: Human-perceived temperature changes over South China: Long-term trends and urbanization effects. Atmos. Res., 215, 116-127, doi:10.1016/j.atmosres.2018.09.006.

Wang, Y., B. Zhou, D. Qin, J. Wu, R. Gao, and L. Song, 2017: Changes in mean and extreme temperature and precipitation over the arid region of Northwestern China: Observation and projection. Adv. Atmos. Sci., 34, 289-305, doi:10.1007/ s00376-016-6160-5.

Wichmann, J., Z. Andersen, M. Ketzel, T. Ellermann, and S. Loft, 2011: Apparent temperature and cause-specific emergency hospital admissions in greater Copenhagen, Denmark. PLoS One, 6, e22904, doi:10.1371/journal.pone.0022904.

Wu, J., J. Zha, and D. Zhao, 2017a: Evaluating the effects of land use and cover change on the decrease of surface wind speed over China in recent 30 years using a statistical downscaling method. Climate Dyn., 48, 131-149, doi:10.1007/s00382016-3065-z.

Wu, J., X. Gao, F. Giorgi, and D. Chen, 2017b: Changes of effective temperature and cold/hot days in late decades over China based on a high resolution gridded observation dataset. Int. J. Climatol., 37, 788-800, doi:10.1002/joc.5038.

Xia, J., K. Tu, Z. Yan, and Y. Qi, 2016: The super-heat wave in eastern China during July-August 2013: A perspective of climate change. Int. J. Climatol., 36, 1291-1298, doi:10.1002/ joc. 4424 .

Zhang, M., J. He, B. Wang, S. Wang, S. Li, W. Liu, and X. Ma, 2013: Extreme drought changes in Southwest China from 1960 to 2009. J. Geogr. Sci., 23, 3-16, doi:10.1007/s11442013-0989-7.

Zhang, Q., C.-Y. Xu, and Z. Zhang, 2009: Observed changes of drought/wetness episodes in the Pearl River basin, China, using the standardized precipitation index and aridity index. Theor. Appl. Climatol., 98, 89-99, doi:10.1007/s00704-0080095-4.

Zhou, Y., and G. Ren, 2011: Change in extreme temperature event frequency over mainland China, 1961-2008. Climate Res., 50, 125-139, doi:10.3354/cr01053.

Manuscript received 2 December 2018, accepted 23 January 2019 SOLA: https://www.jstage.jst.go.jp/browse/solal 